C2018, Elsevier. This manuscript version is made available under the CC-BY-NC-ND 4.0 license http://creativecommons.org/licenses/by-nc-nd/4.0/

\title{
Survey of Midwives' perinatal mental health knowledge, confidence, attitudes and learning needs.
}

\begin{abstract}
Background: Midwives have a primary role in facilitating the first stage of perinatal mental health risk reduction through inquiring about perinatal mental health, identifying risk factors and current perinatal mental health problems, providing support or crisis intervention, referring for treatment and decreasing stigmatisation.
\end{abstract}

Aims. The aims of this study were to determine midwives' a) knowledge of and confidence to identify and manage perinatal mental health problems, b) attitudes towards women who experience severe mental illness and c) perceived learning needs.

Design: A cross-sectional survey design.

Methods: The study was conducted between September 2016 and April 2017 in seven Maternity services in the Republic of Ireland with a purposeful non-random convenience sample of midwives ( $\mathrm{n}=157)$. Data was anonymously collected utilising the Perinatal Mental Health Questionnaire, the Mental Illness: Clinician's Attitudes scale and the Perinatal Mental Health Learning Needs questionnaire.

Findings: Midwives indicated high levels of knowledge (71.1\%) and confidence (72\%) in identifying women who experience depression and anxiety however, they reported less confidence in caring (43.9\%) for women. Only $17.8 \%(n=28)$ of midwives felt equipped to support women whilst $15.3 \%$ $(n=24)$ reported having access to sufficient information. Midwives desire education on the spectrum of perinatal mental health problems. The mean score for the Mental Illness: Clinician's Attitudes scale was $36.31(\mathrm{SD}=7.60)$, indicating positive attitudes towards women with severe mental illness.

Conclusion: Midwives require further education on perinatal mental health across cultures with a skill focus and which explores attitudes delivered in a study day format.

Keywords: Perinatal mental health; Midwifery; Knowledge; Confidence; Attitudes; Learning needs 
Statement of significance

\section{Problem or Issue}

A midwife's attitude towards women who experience perinatal mental health problems influences effective perinatal mental health care provision.

\section{What is Already known}

Internationally, midwives report-varying levels of confidence, knowledge, attitudes and skills in caring for women experiencing perinatal mental health problems.

\section{What this Paper Adds}

The study provides insight into midwives' attitudes to severe mental illness and adds to the international discussion on how best to prepare midwives for a role in perinatal mental health. 


\section{Introduction}

Perinatal mental health $(\mathrm{PMH})$ refers to the mental health of women from conception through the first postnatal year and this period is recognised as a uniquely opportune time for perinatal mental health interventions ${ }^{1}$. The term perinatal mental health problems (PMHPs) describes the scope of mental health disorders encountered by women from psychological distress to serious mental health problems $^{1,2}$.

Prevalence rates of PMHPs in Ireland have been reported for postnatal depression (PND) and range from $13.2 \%$ at six weeks and $9.8 \%$ at twelve weeks ${ }^{3}$. Moreover, the first UK study ${ }^{4}$ examining the incidence of PMHPs in women assessed by a midwife using the Whooley questions at the initial antenatal visit reported the population prevalence as $27 \%$ (95\% CI 22-32) equating to $1: 4$ women. Rates of PMHPs reported: antenatal depression 11\% (95\% CI 8-14\%), anxiety disorders 15\% (95\% CI 11-19\%), obsessive compulsive disorder $2 \%$ (95\% CI 1-4\%), post- traumatic stress disorder $0.8 \%$ (95\% CI 0-1\%), eating disorders $2 \%$ (95\% CI .4-3\%), bipolar disorder 1 0.3\% (95\% CI .1-1\%), bipolar $110.3 \%$ (95\% CI .1-1\%) and borderline personality $0.7 \%(95 \% \text { CI } 0-1 \%)^{4}$.

PMHPs are associated with significant morbidity, affecting the wellbeing of the woman, her baby and significant others. Adverse outcomes for women who experience PMHPs include recurrent depression, increased risk of serious mental health problems, less responsive care giving and increased risk of suicide $^{5}$. For infants, research has identified epigenetic modifications, preterm birth, low birth weight, adverse effect on cognitive, behavioural, psychomotor and socio-emotional development, child and adult psychiatric conditions and rarely child neglect, abuse and neonaticide as impacts of PMHPs $6,7,8$. Paternal perinatal depression and poor relationship satisfaction have been linked to maternal mental health issues ${ }^{9}$.Therefore; the perinatal period is identified as a potentially high-risk period and PMH as a major public health issue ${ }^{1,5}$.

\section{Identification of PMHPs}


Early identification of PMHPs during pregnancy and appropriate interventions are fundamental steps in a strategy that aims to promote optimal fetal and infant development ${ }^{10,11,12}$. Screening, clear referral processes, access to specialist's PMH services and community resources are required to provide effective PMH care ${ }^{10,11,12}$. Although the perinatal period is a time of increased healthcare utilisation and offers midwives a unique opportunity to identify risk factors for PMHPs and enquire about the woman's perinatal mental wellbeing, there is currently no international agreement on screening, screening instruments or timing of screening for PMHPs ${ }^{13}$. However, international

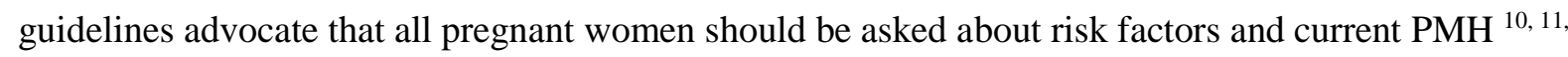
${ }^{13}$ as the greatest barrier to providing appropriate care and support to women experiencing PMHPs is the low level of identification of need ${ }^{12}$.

Midwives caring for women in the perinatal period are challenged with identifying both women presenting with a pre-existing mental health problem and those for whom childbearing results in the onset of a PMH issue. Thereby, midwives are required to extend their knowledge beyond the traditional remit of postnatal depression and identify PMHPs across the spectrum. Screening for PMHPs in maternity settings has been found to be acceptable to women and healthcare professionals ${ }^{12}$, ${ }^{14}$. However, there is also evidence that the way in which midwives ask screening questions determines the acceptability of screening for women and screening should only be implemented when midwives have received appropriate training and have access to referral and integrated care pathways ${ }^{4}$. Screening of women's past mental health history and current PMH is associated with appropriate referral rates rather than a non-specific inflation of referrals such as false positives which have resource implications ${ }^{13,15}$.Though it is important that midwives are confident and skilled in assessing and managing lower levels of distress appropriately ${ }^{15,16,17,18,19}$. Barriers to caring for women who experience PMHPs have been identified among midwives across international studies and include; varying levels of confidence, knowledge, attitudes and skills, insufficient training, inconsistent team working, time pressures, lack of knowledge of resources, limited links with mental health services and inconsistencies, and discontinuities in the system ${ }^{12,16,17,18,19,20}$. 
Internationally, minimal research has examined midwives' attitudes to women who experience PMHPs $^{18,19,20}$. In Ireland midwives have an enhanced public health role in the provision of PMH care as they frequently interact with women and an understanding of midwives' knowledge, attitudes and practice in relation to $\mathrm{PMH}$ can be used to plan PMH service and training. Obtaining evidence on midwives' knowledge of and confidence to identify and manage PMHPs, their attitudes towards women who experience severe mental health problems and perceived training needs relating to $\mathrm{PMH}$ ensures that education strategies and professional development opportunities are tailored to the needs of the midwifery workforce ${ }^{20}$.

\section{Methods}

\subsection{Design}

A cross-sectional study utilising a paper-based questionnaire was administered to a purposeful nonrandom convenience sample of midwives in the Republic of Ireland. The conduct and reporting of this study is guided by STROBE - Strengthening the Reporting of Observational Studies in Epidemiology guidelines ${ }^{21}$.

\subsection{Aim}

The aims of this study were to determine midwives' knowledge of and confidence to identify and manage perinatal mental health problems (PMHPs), their attitudes towards women who experience severe mental illness, and to explore midwives perceived training needs.

\subsection{Participants and setting}

A purposeful sample of midwives working within seven maternity services in Ireland (one maternity hospital and six maternity units within general hospitals) were invited to participate ( $n=428)$. The inclusion criteria were that participants must be registered with the Nursing and Midwifery Board of Ireland and working with women and babies. Recruitment occurred between September 2016 and April 2017 and the Directors of Nursing/Midwifery granted access. An appointed gatekeeper distributed the study pack (invitation letter, information sheet and questionnaire) which were returned 
to a collection box in each area. No identifiable information was requested and consent was implied by returning completed questionnaires. Research ethics approval was obtained from three research ethics committees covering the seven maternity services within the study.

\subsection{Data collection}

Data was collected over an eight-month period through an anonymous questionnaire, which took 1020 minutes to complete.

\subsection{Survey instrument}

The questionnaire combined psychometrically tested scales and sections developed by the researchers after an integrative review of the literature was completed ${ }^{19}$. The questionnaire was piloted with ten midwives who provided feedback on clarity, content, format of questions and completion time. An expert panel consisting of eight healthcare professionals and educationalists completed the Content Validity Index (CVI) and clarity questionnaire. Feedback from the pilot and expert panel resulted in minor changes to the demographic section, wording, question ordering and open-ended questions.

\subsection{Survey structure}

The survey comprised seven sub-sections:

\subsubsection{Socio-demographics}

Socio-demographic information including; gender, age, qualification, number of years worked as a midwife, work pattern, current employment service area (i.e. antenatal, intrapartum, postnatal), highest educational level attained, recent post-registration PMH education, how often they worked with women who experience PMHPs and whether they knew someone or had a personal experience of a mental health problem.

\subsubsection{The Perinatal Mental Health Questionnaire (PMHQ)}


The PMHQ consists of validated scales; the Perinatal Mental Health Awareness (PMHA) scale, the causes scale, the consequences scale and Professional Issues in Maternal Mental Health Scale (PIMMHS).

\subsection{2a The Perinatal Mental Health Awareness (PMHA) scale}

The Perinatal Mental Health Awareness (PMHA) scale (9-item) consisting of three correlated subscales (i) mental health (PMHA -SAD) (ii) physical health (PMHA-MED) and (iii) learning/intellectual disability (PMHA-LD) ${ }^{22}$. This scale represents key attributes (i) knowledge (ii) confidence in identification and (iii) confidence in management of mental health issues ${ }^{22}$. PMHA scale is Likert scored from "very knowledgeable, knowledgeable, not very knowledgeable, not knowledgeable". Cronbach's alpha has been reported as 0.79, with subscales PMHA-SAD 0.68, PMHA-MED 0.77, PMHA-LD $0.78^{22}$.

2.6.2b The Causes sub-scale (17-item) examines personal ideas about aetiology of PMHPs and is Likert scored from "strongly agree, agree, neither agree nor disagree, disagree, strongly disagree".

2.6.2c The Consequences sub-scale (7-item) examines the expected effects and outcome on the life of a woman experiencing PMHPs and is Likert scored from "strongly agree, agree, neither agree nor disagree, disagree, strongly disagree". The scale was adapted from the revised illness perception questionnaire (IPQ-R) (Moss-Morris et al. 2002) by Jomeen et al. ${ }^{23}$. Confirmatory factor analysis (CFA) was undertaken to determine model fit and parsimony, which identified a CFI 0.93 for the consequences subscale ${ }^{23}$.

2.6.2d Professional issues in maternal mental health scale (PIMMHS) ${ }^{24}$ (7-item) comprising of two Sub-scales of emotion/communication (PIMMHS-Emotion sub-scale) and training (PIMMHSTraining sub-scale) assessing the perception of professional issues associated with provision of PMH care. PIMMHS is Likert scored from "strongly agree, agree, neither agree nor disagree, disagree, strongly disagree" where higher scores indicate greater agreement with professional aspects of care 
provision which would impact positively on the provision of appropriate PMH care and support. Cronbach's alpha of the PIMMHS-Emotion sub-scale has been reported as 0.81 (0.89-0.92) and the PIMMHS-Training sub-scale $0.57(0.48-0.66)^{24}$.

\subsubsection{Mental Illness: Clinicians' Attitudes (MICA-version 4)}

The Mental Illness: Clinicians' Attitudes (MICA-4) scale (16-item) ${ }^{25}$ examines attitudes towards people with severe mental illness and is scored on a Likert scale ranging from "strongly agree, agree, somewhat agree, somewhat disagree, disagree, strongly disagree". A high overall score indicates more negative stigmatising attitudes towards mental illness and psychiatry. Reliability of the scale is reported by internal consistency (Cronbach's alpha 0.72) and item-total correlations $(\geq 0.2)^{25}$.

\subsubsection{Professional development}

Midwives' professional development/learning needs were ascertained from six items developed by Hauck et al. ${ }^{20}$ and adapted for use in this study. A single item (yes/no response) assessed whether midwives felt well equipped to support women with PMHPs and had sufficient access to information on PMH. Midwives were asked to clarify their learning needs by indicating particular disorders, topics and skills they wanted further education on and ranked their preference for the format of PMH continuous professional development (CPD) options.

\subsubsection{Open questions}

In addition, midwives were asked to respond to a series of five questions around availability of guidelines, inquiry into previous history of mental health problems, current symptoms of PMHPs, screening tools used in practice and available referral options.

\subsection{Scoring and data analysis}

Data entry and analysis was performed using the Statistical Package for Social Science (SPSS)

Version 24. All data was checked for completeness and consistency and a 10\% random comparison between the online data and the original paper based questionnaires was conducted by MN to ensure 
accuracy of data coding and entry. Descriptive statistics (frequencies, percentages, means and standard deviations) were calculated using SPSS for demographic data, knowledge, confidence, attitude statements and professional development learning needs. Fisher's exact test were used to identify associations between variables on the PMHA scale.

\section{Findings}

\subsection{Demographic characteristics}

A total of 157 respondents completed the survey, representing a $36.7 \%$ response rate. A summary of demographic characteristics of respondents' is presented in Table 1. Only one respondent was male. Half of the midwives $(50.3 \%, \mathrm{n}=79)$ were aged 40 years and older. In terms of qualifications, $74.5 \%$ $(n=117)$ of midwives had dual registration as a nurse and midwife and $25.5 \%(n=40)$ were direct entry midwives. Only $13.4 \%$ of respondents had completed a continuous professional development course relevant to PMH and of these respondent's four had completed the course in the previous 6-12 months. In addition, $63.1 \%(n=99)$ of the respondents reported having a personal history of mental health through friend, family or self. 
Table 1. Demographic variables ( $n=157$ unless stated)

\begin{tabular}{|c|c|c|}
\hline Age & Years worked as a midwife & Education $(n=156)$ \\
\hline $20-29(n=23) 14.7 \%$ & $<1(\mathrm{n}=7) 4.5 \%$ & Certificate $(n=18) 11.5 \%$ \\
\hline $30-39(n=55) 35.0 \%$ & $1-2(n=11) 7.0 \%$ & Diploma $(n=14) 8.9 \%$ \\
\hline $40-49(n=39) 24.8 \%$ & $2-5(n=31) 19.7 \%$ & Degree $(n=58) 36.9 \%$ \\
\hline \multirow[t]{2}{*}{$50-55->(n=40) 25.5 \%$} & $5-10(n=25) 15.9 \%$ & Postgraduate diploma $(n=52) 33.1 \%$ \\
\hline & $>10(\mathrm{n}=83) 52.9 \%$ & Masters $(n=14) 8.9 \%$ \\
\hline Education on PMH & Work pattern & Contact with women with PMHPs \\
\hline Yes $(n=21) 13.4 \%$ & Full-time $(n=108) 68.8 \%$ & Very often/frequently $(\mathrm{n}=87) 55.4 \%$ \\
\hline \multirow[t]{2}{*}{ No $(n=136) 86.6 \%$} & Reduced hours $(n=49) 31.2 \%$ & Sometimes $(n=60) 38.2 \%$ \\
\hline & & Rarely/never $(n=10) 6.4 \%$ \\
\hline \multicolumn{2}{|c|}{ Qualifications held } & Current area of practice $(n=157)$ \\
\hline \multicolumn{2}{|c|}{ Registered Midwife ( $\mathrm{n}=157) 100 \%$} & etween practice areas $(n=64) 40.8 \%$ \\
\hline \multicolumn{2}{|c|}{ Registered General Nurse $(n=117) 74.5 \%$} & Antenatal $(n=18) 11.4 \%$ \\
\hline \multicolumn{2}{|c|}{ Registered Psychiatric Nurse $(n=2) 1.4 \%$} & Intranatal $(n=28) 17.8 \%$ \\
\hline \multicolumn{2}{|c|}{ Registered Children's Nurse $(n=5) 3.6 \%$} & Postnatal $(n=23) 14.6 \%$ \\
\hline \multicolumn{2}{|c|}{ Registered Nurse Intellectual Disabilities ( $\mathrm{n}=1$ ) } & NICU $(n=11) 7.0 \%$ \\
\hline \multicolumn{2}{|c|}{$0.7 \%$} & o/homebirth services $(n=7) 4.5 \%$ \\
\hline \multicolumn{2}{|c|}{ Public Health Nurse $(n=1) 0.7 \%$} & Other $(n=6) 3.8 \%$ \\
\hline \multicolumn{3}{|c|}{ Registered Nurse Prescriber $(n=3) 2.2 \%$} \\
\hline \multicolumn{3}{|c|}{ Personal experience of mental health issues (through friend, family or self) } \\
\hline \multicolumn{3}{|l|}{ Yes $(n=99) 63.1 \%$} \\
\hline No $(n=58) 36.9 \%$ & & \\
\hline
\end{tabular}




\subsection{The Perinatal Mental Health Awareness (PMHA) scale}

The level of knowledge and confidence reported by midwives in advising and caring for women with PMHPs is presented in Table 2. Over half of the midwives $(63.2 \%, n=98)$ perceived themselves to be knowledgeable on stress, anxiety and depression and 8.4\% ( $\mathrm{n}=13)$ very knowledgeable. Just over a quarter of midwives reported not being very knowledgeable of these conditions (28.4\%, $n=44)$. In contrast, only $1.3 \%(\mathrm{n}=2)$ indicated that they were not knowledgeable of medical/obstetric complications. In relation to learning disabilities $60.6 \%$ of midwives reported not being very knowledgeable. The majority of midwives indicated that they were very confident $(13.5 \%, \mathrm{n}=21)$ or confident $(59.4 \%, \mathrm{n}=92)$ in identifying stress, anxiety and depression however approximately half of midwives $(55.5 \%, \mathrm{n}=86)$ reported not being confident in managing stress, anxiety and depression. In comparison, only $3.2 \%$ reported a low level of confidence in managing medical/obstetric complications. Using Fisher's exact test, a significant association $(\mathrm{P}<.000)$ was found to exist where midwives who reported that they were very knowledgeable also reported that they were very confident to identify stress, anxiety and depression. Similarly, being very knowledgeable was significantly associated with (Fisher's Exact test, $\mathrm{p}<.000$ ) being very confident to manage PMHPs. 
Table 2. Perinatal Mental Health Awareness scale $(K=$ knowledgeable, $C=$ confident $)(n=155)$

$\operatorname{Very}(\mathrm{K} / \mathrm{C}) \quad \mathrm{K} / \mathrm{C} \quad$ Not very $\quad \operatorname{Not}(\mathrm{K} / \mathrm{C})$

(K/C)

How knowledgeable are you about the following conditions

$\begin{array}{lllll}\text { Stress, anxiety and depression } & \mathrm{n}=13,8.4 \% & \mathrm{n}=98,63.2 \% & \mathrm{n}=42,27.1 \% & \mathrm{n}=2,1.3 \% \\ \text { Learning disabilities } & \mathrm{n}=4,2.6 \% & \mathrm{n}=44,28.4 \% & \mathrm{n}=94,60.6 \% & \mathrm{n}=13,8.4 \% \\ \text { Medical, obstetric complications } & \mathrm{n}=88,56.8 \% & \mathrm{n}=65,41.9 \% & \mathrm{n}=2,1.3 \% & \mathrm{n}=0,0 \%\end{array}$

How confident are you in identifying the following conditions

$\begin{array}{lllll}\text { Stress, anxiety and depression } & \mathrm{N}=21,13.5 \% & \mathrm{~N}=92,59.4 \% & \mathrm{~N}=40,25.8 \% & \mathrm{~N}=2,1.3 \% \\ \text { Learning disabilities } & \mathrm{N}=9,5.8 \% & \mathrm{~N}=81,52.3 \% & \mathrm{~N}=61,39.3 \% & \mathrm{~N}=4,2.6 \% \\ \text { Medical, obstetric complications e } & \mathrm{N}=88,56.8 \% & \mathrm{~N}=62,40 \% & \mathrm{~N}=4,2.6 \% & \mathrm{~N}=1, .6 \%\end{array}$

How confident are you in managing the following conditions

\begin{tabular}{lllll} 
Stress, anxiety and depression & $\mathrm{N}=6,3.9 \%$ & $\mathrm{~N}=63,40.6 \%$ & $\mathrm{~N}=78,50.3 \%$ & $\mathrm{~N}=8,5.2 \%$ \\
Learning disabilities & $\mathrm{N}=3,1.9 \%$ & $\mathrm{~N}=41,26.5 \%$ & $\mathrm{~N}=94,60.6 \%$ & $\mathrm{~N}=17,11 \%$ \\
Medical, obstetric complications & $\mathrm{N}=67,43.2 \%$ & $\mathrm{~N}=83,53.5 \%$ & $\mathrm{~N}=3,1.9 \%$ & $\mathrm{~N}=2,1.3 \%$ \\
\hline
\end{tabular}




\subsection{Causes - Factors causing PMHPs}

The Causes sub-scale identified which factors midwives perceive as having a casual or contributory role in PMHPs. The most frequently rated factor was stress and worry followed by a major life event. Only $4.5 \%(n=7)$ of respondents did not identify a psychiatric history as a cause of PMHPs and $13.4 \%$ $(n=21)$ neither agreed nor disagreed with this statement. Furthermore, $9.6 \%(n=15)$ of respondents disagreed that a family history of PMHPs is linked to PMHPs and 28\% $(\mathrm{n}=44)$ neither agreed nor disagreed with this statement. In relation to low social support $7.6 \%(n=12)$ of respondents disagreed that this was a contributory factor to PMHPs.

\subsection{Consequences of PMHPs}

There was a perception among most midwives that PMHPs had major consequences for those women who experience a PMH disorder $(94.9 \%, n=148)$ with just $8.9 \%(n=14)$ agreeing with the statement that PMHPs do not have much effect on the lives of women who have them. Midwives agreed that PMHPs impact on maternal fetal attachment $(87.8 \%, \mathrm{n}=137)$.

\subsection{Professional issues in maternal mental health scale (PIMMHS)}

A total of $70.4 \%(n=109)$ respondents who completed the scale $(n=155)$ agreed with the statement 'I know exactly who to contact if a person is experiencing mental health problems'. However, $22.1 \%$ $(n=34)$ of respondents disagreed with the statement 'it is easy for me to obtain help for women with mental health problems'. While $16.2 \%(\mathrm{n}=25)$ of respondents were reluctant to discuss emotional problems that a woman might be having because they would not know what to do or who to ask for advice. In relation to the question 'training pays sufficient attention to the cultural dimension of pregnancy, birth and postnatal' $50.6 \%(\mathrm{n}=78)$ of respondents disagreed with this statement. 
Furthermore, only $3.9 \%(n=6)$ of midwives agreed that training equips midwives to manage the mental health needs of women from different cultural backgrounds. Time was identified as a barrier to engaging in a discussion about emotional issues for $35.7 \%(n=55)$ of respondents while $20.6 \%(n=32)$ of respondents identified feeling uncomfortable discussing emotional problems with the woman.

\subsection{Attitudes - Mental Illness: Clinicians’'Attitudes (MICA-version 4)}

The mean score for the MICA-4 was 36.31 ( $\mathrm{SD}=7.6)$. The majority of midwives reported that they would not mind working with a colleague with severe mental illness but would be hesitant to disclose a personal diagnosis of mental illness. In response to the statement "If I had a mental illness, I would never admit this to my friends because I would fear being treated differently" $37.9 \%(\mathrm{n}=58)$ of midwives agreed (somewhat agree, agree, strongly agree) and 60.5\% ( $\mathrm{n}=92)$ agreed that "If I had a mental illness I would never admit this to my colleagues for fear of being treated differently". While the majority of midwives $81 \%(\mathrm{n}=124)$ disagreed that "People with a severe mental illness are dangerous more often than not", $53.1 \%(\mathrm{n}=80)$ of respondents somewhat disagreed, disagreed or strongly disagreed with the statement "The public does not need to be protected from people with a severe mental illness". Midwives regarded psychiatry in high status when compared to other fields of health and social care (Table 3). 
Table 3. $\mathrm{MICA}-4$ (St $A=$ strongly agree,$A=$ agree, So $A=$ somewhat agree, So $D=$ somewhat disagree, $\mathrm{D}=$ disagree, $\mathrm{St} \mathrm{D}=$ strongly disagree)

\begin{tabular}{|c|c|c|c|c|c|c|}
\hline & St A & A & So $\mathrm{A}$ & So $\mathrm{D}$ & D & St D \\
\hline $\begin{array}{l}\text { I just learn about mental health when I } \\
\text { have to, and would not bother reading } \\
\text { additional material on it }\end{array}$ & $\begin{array}{l}1 \\
(.6 \%)\end{array}$ & $\begin{array}{l}11 \\
(7.1 \%)\end{array}$ & $\begin{array}{l}49 \\
(31.8 \%)\end{array}$ & $\begin{array}{l}25 \\
(16.2 \%)\end{array}$ & $\begin{array}{l}54 \\
(35.1 \%)\end{array}$ & $\begin{array}{l}14 \\
(9.1 \%)\end{array}$ \\
\hline $\begin{array}{l}\text { People with severe mental illness can never } \\
\text { recover enough to have a good quality of } \\
\text { life }\end{array}$ & $\begin{array}{l}1 \\
(.6 \%)\end{array}$ & $\begin{array}{l}1 \\
(.6 \%)\end{array}$ & $\begin{array}{l}12 \\
(7.8 \%)\end{array}$ & $\begin{array}{l}20 \\
(13 \%)\end{array}$ & $\begin{array}{l}74 \\
(48.1 \%)\end{array}$ & $\begin{array}{l}46 \\
(29.9 \%)\end{array}$ \\
\hline $\begin{array}{l}\text { Working in the mental health field is just as } \\
\text { respectable as other fields of health and } \\
\text { social care }\end{array}$ & $\begin{array}{l}92 \\
(60.1 \%)\end{array}$ & $\begin{array}{l}48 \\
(31.4 \%)\end{array}$ & $\begin{array}{l}6 \\
(3.9 \%)\end{array}$ & $\begin{array}{l}1 \\
(.7 \%)\end{array}$ & $\begin{array}{l}5 \\
(3.3 \%)\end{array}$ & $\begin{array}{l}1 \\
(.7 \%)\end{array}$ \\
\hline $\begin{array}{l}\text { If I had a mental illness, I would never } \\
\text { admit this to my friends because I would } \\
\text { fear being treated differently }\end{array}$ & $\begin{array}{l}4 \\
(2.6 \%)\end{array}$ & $\begin{array}{l}18 \\
(11.8 \%)\end{array}$ & $\begin{array}{l}36 \\
(23.5 \%)\end{array}$ & $\begin{array}{l}27 \\
(17.6 \%)\end{array}$ & $\begin{array}{l}48 \\
(31.4 \%)\end{array}$ & $\begin{array}{l}20 \\
(13.1 \%)\end{array}$ \\
\hline $\begin{array}{l}\text { People with severe mental illness are } \\
\text { dangerous more often than not }\end{array}$ & $\begin{array}{l}2 \\
(1.3 \%)\end{array}$ & $\begin{array}{l}5 \\
(3.3 \%)\end{array}$ & $\begin{array}{l}22 \\
(14.4 \%)\end{array}$ & $\begin{array}{l}30 \\
(19.6 \%)\end{array}$ & $\begin{array}{l}58 \\
(37.9 \%)\end{array}$ & $\begin{array}{l}36 \\
(23.5 \%)\end{array}$ \\
\hline $\begin{array}{l}\text { Health/social care staff know more about } \\
\text { the lives of people treated for a mental } \\
\text { illness than do family members or friends. }\end{array}$ & $\begin{array}{l}4 \\
(2.6 \%)\end{array}$ & $\begin{array}{l}13 \\
(8.6 \%)\end{array}$ & $\begin{array}{l}43 \\
(28.3 \%)\end{array}$ & $\begin{array}{l}24 \\
(15.8 \%)\end{array}$ & $\begin{array}{l}47 \\
(30.9 \%)\end{array}$ & $\begin{array}{l}21 \\
(13.8 \%)\end{array}$ \\
\hline $\begin{array}{l}\text { If I had a mental illness, I would never } \\
\text { admit this to my colleagues for fear of } \\
\text { being treated differently }\end{array}$ & $\begin{array}{l}14 \\
(9.2 \%)\end{array}$ & $\begin{array}{l}28 \\
(18.4 \%)\end{array}$ & $\begin{array}{l}50 \\
(32.9 \%)\end{array}$ & $\begin{array}{l}18 \\
(11.8 \%)\end{array}$ & $\begin{array}{l}36 \\
(23.7 \%)\end{array}$ & $\begin{array}{l}6 \\
(3.9 \%)\end{array}$ \\
\hline $\begin{array}{l}\text { Being a health/social care professional in } \\
\text { the area of mental health is not like being a } \\
\text { real health/social care professional }\end{array}$ & & $\begin{array}{l}3 \\
(2 \%)\end{array}$ & $\begin{array}{l}2 \\
(1.3 \%)\end{array}$ & $\begin{array}{l}14 \\
(9.2 \%)\end{array}$ & $(28.9 \%$ & $\begin{array}{l}89 \\
(58.6 \%)\end{array}$ \\
\hline
\end{tabular}




\begin{tabular}{|c|c|c|c|c|c|c|}
\hline $\begin{array}{l}\text { If a senior colleague instructed me to treat } \\
\text { people with a mental illness in a } \\
\text { disrespectful manner, I would not follow } \\
\text { their instructions }\end{array}$ & $\begin{array}{l}130 \\
(85 \%)\end{array}$ & $\begin{array}{l}16 \\
(10.5 \%)\end{array}$ & $\begin{array}{l}2 \\
(1.3 \%)\end{array}$ & 0 & $\begin{array}{l}1 \\
(.7 \%)\end{array}$ & $\begin{array}{l}4 \\
(2.6 \%)\end{array}$ \\
\hline $\begin{array}{l}\text { I feel as comfortable talking to a person } \\
\text { with a mental illness as I do talking to a } \\
\text { person with a physical illness }\end{array}$ & $\begin{array}{l}42 \\
(27.5 \%)\end{array}$ & $\begin{array}{l}46 \\
(30.1 \%)\end{array}$ & $\begin{array}{l}35 \\
(22.9 \%)\end{array}$ & $\begin{array}{l}20 \\
(13.1 \%)\end{array}$ & $\begin{array}{l}8 \\
(5.2 \%)\end{array}$ & 2 \\
\hline $\begin{array}{l}\text { It is important that any health/social care } \\
\text { professional supporting a person with a } \\
\text { mental illness also ensures that their } \\
\text { physical health is assessed }\end{array}$ & $\begin{array}{l}71 \\
(46.7 \%)\end{array}$ & $\begin{array}{l}71 \\
(46.7 \%)\end{array}$ & $\begin{array}{l}8 \\
(5.3 \%)\end{array}$ & 0 & 2 & 0 \\
\hline $\begin{array}{l}\text { The public does not need to be protected } \\
\text { from people with a severe mental illness }\end{array}$ & $\begin{array}{l}12 \\
(7.9 \%)\end{array}$ & $\begin{array}{l}25 \\
(16.6 \%)\end{array}$ & $\begin{array}{l}34 \\
(22.5 \%)\end{array}$ & $\begin{array}{l}38 \\
(25.2 \%)\end{array}$ & $\begin{array}{l}33 \\
(21.9 \%)\end{array}$ & $\begin{array}{l}9 \\
(6 \%)\end{array}$ \\
\hline $\begin{array}{l}\text { If a person with a mental illness complained } \\
\text { of physical symptoms (such as chest pain) I } \\
\text { would attribute it to their mental illness }\end{array}$ & $\begin{array}{l}1 \\
(.7 \%)\end{array}$ & $\begin{array}{l}1 \\
(.7 \%)\end{array}$ & $\begin{array}{l}7 \\
(4.6 \%)\end{array}$ & $\begin{array}{l}19 \\
(12.5 \%)\end{array}$ & $\begin{array}{l}57 \\
(37.5 \%)\end{array}$ & $\begin{array}{l}67 \\
(44.1 \%)\end{array}$ \\
\hline $\begin{array}{l}\text { General practitioners should not be } \\
\text { expected to complete a thorough } \\
\text { assessment for people with psychiatric } \\
\text { symptoms because they can be referred to } \\
\text { a psychiatrist }\end{array}$ & $1(.7 \%)$ & $9(6 \%)$ & $\begin{array}{l}10 \\
(6.6 \%)\end{array}$ & $\begin{array}{l}9 \\
(6.0 \%)\end{array}$ & $\begin{array}{l}64 \\
(42.4 \%)\end{array}$ & $\begin{array}{l}58 \\
(38.4 \%)\end{array}$ \\
\hline $\begin{array}{l}\text { I would use the terms 'crazy', 'nutter', } \\
\text { 'mad' etc. to describe to colleagues, people } \\
\text { with a mental illness who I have seen in my } \\
\text { work }\end{array}$ & $\begin{array}{l}4 \\
(2.6 \%)\end{array}$ & $\begin{array}{l}1 \\
(.7 \%)\end{array}$ & $\begin{array}{l}14 \\
(9.2 \%)\end{array}$ & $\begin{array}{l}8 \\
(5.3 \%)\end{array}$ & $\begin{array}{l}36 \\
(23.7 \%)\end{array}$ & $\begin{array}{l}89 \\
(58.6 \%)\end{array}$ \\
\hline $\begin{array}{l}\text { If a colleague told me they had a mental } \\
\text { illness, I would still want to work with them }\end{array}$ & $\begin{array}{l}90 \\
(59.2 \%)\end{array}$ & $\begin{array}{l}43 \\
(28.3)\end{array}$ & $\begin{array}{l}13 \\
(8.6 \%)\end{array}$ & $\begin{array}{l}1 \\
(.7 \%)\end{array}$ & $\begin{array}{l}2 \\
(1.3 \%)\end{array}$ & $\begin{array}{l}3 \\
(2 \%)\end{array}$ \\
\hline
\end{tabular}




\subsection{Professional development}

A summary of self-reported PMH learning needs is presented in Table 4. The majority of respondents (79.6\%, $\mathrm{n}=125)$ did not feel well equipped to support women with PMHPs. Furthermore, only 15.3\% $(n=24)$ felt they had sufficient information. Over half of all respondents indicated a need for further education on all of the listed PMHPs with depression $(71.3 \%, \mathrm{n}=112)$ and Schizophrenia $(70.1 \%$, $\mathrm{n}=110$ ) reported most frequently. Similarly, over $60 \%$ of respondents reported a need for additional education on all topics with the highest level of demand for education on impact of childbearing on mental illness $(77.1 \%, \mathrm{n}=121)$. Over $80 \%$ of midwives requested skill development for assessment of mental health and $72.6 \%(n=114)$ for assessment of risk of mental illness. While, $38.9 \%(n=61)$ requested additional skill development for breastfeeding in the context of PMH. Midwives were requested to rank in order their preference for preferred educational format for continuous professional development. The majority of midwives $(35 \%, \mathrm{n}=55)$ identified study days as their preferred format followed closely by mandatory in-service education programmes $(29.9 \%, n=47)$ with just $6.4 \%(n=10)$ reporting a preference for online delivery. 
Table 4: Perinatal mental health learning needs

\begin{tabular}{|c|c|c|}
\hline Variable & $\mathrm{n}$ & $\%$ \\
\hline \multicolumn{3}{|c|}{$\begin{array}{l}\text { Feels well equipped to support women with perinatal mental health } \\
\text { disorders }(n=153)\end{array}$} \\
\hline Yes & 28 & 17.8 \\
\hline No & 125 & 79.6 \\
\hline \multicolumn{3}{|c|}{$\begin{array}{l}\text { Has sufficient access to information on pregnancy and perinatal } \\
\text { mental health disorders }(n=153)\end{array}$} \\
\hline Yes & 24 & 15.3 \\
\hline No & 129 & 82.2 \\
\hline \multicolumn{3}{|c|}{ Mental health disorders -additional education desired $(n=157)$} \\
\hline Depression & 112 & 71.3 \\
\hline Schizophrenia & 110 & 70.1 \\
\hline Bipolar disorder & 102 & 65 \\
\hline Personality disorder & 101 & 64.3 \\
\hline Anxiety disorder & 98 & 62.4 \\
\hline Substance related disorder & 96 & 61.1 \\
\hline Tocophobia & 93 & 59.2 \\
\hline Other & 3 & 1.9 \\
\hline No further training required & 0 & 0 \\
\hline \multicolumn{3}{|c|}{ Topics additional education desired $(n=157)$} \\
\hline Impact of childbearing on mental illness & 121 & 77.1 \\
\hline Understanding service options & 119 & 75.8 \\
\hline Signs and symptoms & 115 & 73.2 \\
\hline Roles of other healthcare professionals & 97 & 61.8 \\
\hline
\end{tabular}




\begin{tabular}{|c|c|c|}
\hline Child safety & 96 & 61.1 \\
\hline Other & 3 & 1.9 \\
\hline No additional knowledge required & 0 & 0 \\
\hline \multicolumn{3}{|l|}{ Skills - additional education required $(n=157)$} \\
\hline Assessment of mental health & 128 & 81.5 \\
\hline Assessment of risk of mental illness & 114 & 72.6 \\
\hline Handling stress and aggression & 111 & 70.1 \\
\hline Discharge planning & 94 & 59.9 \\
\hline Clinical management & 91 & 58 \\
\hline Working with families and carers & 84 & 53.5 \\
\hline Communication skills & 78 & 49.7 \\
\hline Support with breastfeeding & 61 & 38.9 \\
\hline Other & 0 & 0 \\
\hline No additional skills required & 0 & 0 \\
\hline \multicolumn{3}{|l|}{ Preferred educational format ( $1^{\text {st }}$ choice) $(157)$} \\
\hline Study days & 55 & 35 \\
\hline Mandatory in-service education programme & 47 & 29.9 \\
\hline Skills workshop & 33 & 21 \\
\hline Postgraduate module & 20 & 12.7 \\
\hline Seminars & 12 & 7.6 \\
\hline Online & 10 & 6.4 \\
\hline Other & 1 & 0.6 \\
\hline
\end{tabular}




\subsection{Open questions}

In response to open questions, $40.4 \%$ ( $\mathrm{n}=63$ ) of midwives had access to policy/guidelines on $\mathrm{PMH}$, the majority of midwives $(72.6 \%, \mathrm{n}=114)$ ask women about a previous history of mental health problems and $58.6 \%(n=92)$ ask about current symptoms of PMHPs, which drops, to $47.1 \%(n=74)$ of midwives who routinely inquire about current symptoms of PMHPs at routine follow up antenatal and postnatal visits. Furthermore, $77 \%(\mathrm{n}=120)$ indicated that they do not use a screening tool when screening for current symptoms of PMH issues with only one midwife referring to using the Whooley questions ${ }^{26}$ and $16.6 \%(\mathrm{n}=26)$ midwives referencing the Edinburgh Postnatal Depression Scale (EPDS) ${ }^{27}$ Referral to the Psychiatric Liaison Nurse $(44.6 \%, \mathrm{n}=70)$ was the most common referral option reported by midwives followed by referral to the psychiatric team $(29.8 \%, n=46)$. Only $1.3 \%(n=2)$ of midwives had access to specialists PMH midwives.

\section{Discussion}

This study aimed to examine midwives' knowledge of and confidence to identify and care for women who experience PMHPs, their attitudes towards women who experience severe mental illness, and their perceived training needs relating to PMH. The findings of this study show relatively high levels of knowledge in relation to depression and anxiety and positive attitudes towards women with severe mental illness among midwives. Midwives desire further education on PMH across cultures and across the spectrum of PMHPs to include a skills and attitude component in the format of study days.

\subsection{Knowledge and confidence}

Within this study, the majority of midwives reported that they were very knowledgeable of high prevalence mental health disorders. Internationally, previous conceptualisations of PMHPs in practice and in undergraduate education programmes had a limited focus and primarily concentrated on postnatal depression ${ }^{19}$. This might explain why over $70 \%$ of midwives reported they were 
knowledgeable about stress, anxiety and depression however indicated high education needs for the spectrum of PMHPs. Similarly, in previous studies midwives have reported high awareness of perinatal depression ${ }^{28,29}$. Internationally the focus has now moved from postnatal depression to encompass the full spectrum of PMHPs ${ }^{1,4}$. Midwives also reported good knowledge of the consequences and causes of PMHPs though, $18 \%$ of midwives did not agree that a psychiatric history and $38.1 \%$ did not agree that a family history is a contributory factor to PMHPs, both of which are identified across the international research literature as high-risk factors for the development of PMHPs ${ }^{6}$.

Our findings highlight knowledge alone does not reflect midwives' preparation to provide effective PMH care ${ }^{20}$. Only $17.8 \%$ of midwives felt well equipped to support women. Furthermore, there was evidence from the PIMMHS that previous education did not prepare midwives to respond to the PMH needs of women from different cultural backgrounds. Midwives are now only grappling with the foundations of mental health and must extend their knowledge and skills to understand and respond to women's psychological distress from all ethnic backgrounds. This is supported in the literature where women reported that midwives appeared to lack the knowledge and skills to respond sensitively and responsively to psychological needs ${ }^{30}$.

\subsection{Screening and $\mathrm{PMH}$}

The majority of midwives reported a need for further information on PMH and this may be explained by the finding that only $40.4 \%$ of midwives had access to local or national PMH guidelines at the time of the study. It may also explain the low use of screening tools to identify current symptoms of depression or anxiety. Findings demonstrate substantial variation in screening practices with $77 \%$ of midwives indicating that they do not use a screening tool to enquire about current symptoms of mental health issues with only one midwife referring to Whooley questions ${ }^{26}$ and $16.6 \%$ midwives referencing the $\operatorname{EPDS}^{27}$. Cox ${ }^{31}$ suggests that women experiencing moderate to severe perinatal depression will not be identified if screening tools are not part of the assessment process. One of the questions for policy makers and healthcare practitioners is whether universal screening for PMHPs or 
nationally implemented targeted screening is desirable, ethical or practical and sustainable in the long term ${ }^{31}$. Further evidence in the form of effectiveness trials are required to determine whether the potential benefits of perinatal depression and anxiety screening out weight the potential costs and harms of a universal screening programme ${ }^{15,32}$. The potential harms associated with PMH screening include maternal distress, stigma associated with a positive screen and misuse of screening tools as diagnostic resulting in inappropriate referral with resource implications ${ }^{32}$. The wide spectrum of referral options identified by midwives and the limited availability of PMH specialist referral options raises concerns given that screening should be accompanied by the availability of appropriate referral pathways. Higgins et al. ${ }^{30}$ highlight a lack of PMH specialist services and inter-disciplinary referral between maternity and mental health services resulted in women experiencing fragmented care.

\subsection{Professional development needs}

The professional development component of the questionnaire was adapted from work undertaken by Hauck et al. ${ }^{20}$ in Australia. Similar to findings by Hauck et al. ${ }^{20}$ only a minority of midwives felt well equipped to support women with PMHPs and the majority indicated a need for further information. In contrast to findings by Hauck et al. ${ }^{20}$ respondents in this study reported a higher need for skill development. This may be explained by the context of care provision where over the last two decades Australia has taken the lead in developing national public PMH health policy supported by a comprehensive PMH assessment framework, which incorporates guidelines, assessment strategies and is paralleled by training programmes ${ }^{1}$. Ireland has only recently developed best practice principles for midwives $^{33}$, has limited educational opportunities available to midwives and varied access to specialist PMH services exist.

The findings identify the need for further educational opportunities to prepare midwives to optimally fulfil their role in the provision of effective $\mathrm{PMH}$ care. Education has been identified as effective in prevention of PMHPs and midwives who are knowledgeable and confident in relation to PMH are more likely to engage in asking relevant questions and to explore responses in-depth thus ensuring accurate identification and referral of women at risk or currently experiencing PMHPs. Only $13.4 \%$ of 
respondents had received continuous professional development specific to $\mathrm{PMH}$. However, educational interventions alone do not always lead to changes in midwives' attitudes, skills and behaviour required to provide effective PMH care. Noonan et al. ${ }^{19}$ concluded that education programmes would have little benefit if midwives do not have access to integrated PMH care pathways, clinical supervision, mentoring and opportunities for midwives to debrief. Clinical supervision and support pathways for HCPs implementing screening and intervention programs are central components of training and effective PMH training promotes consistency in evidence-based practices, which in turn results in greater equity in access to PMH services for women ${ }^{34}$. The preferred format for education was study days with only $6 \%$ identifying online delivery as their first choice. The high requirement for skill development would lend itself to an interactive component, which midwives may not perceive that online delivery would achieve.

\subsection{Attitudes to mental illness}

The attitudes of midwives who care for women who experience severe PMHPs is important in the context of national and international initiatives aimed at reducing the stigma and exclusion associated with mental illness ${ }^{35}$. Attitudes towards women with mental health problems are influenced by different socio-demographic characteristics such as gender, ethnicity, or knowing someone or having a personal experience of mental illness ${ }^{25,36}$. It is now acknowledged that HCPs involved in providing care to persons with mental health issues may themselves be in need of de-stigmatisation ${ }^{35}$. Negative attitudes held by midwives may influence behaviour, have implications for screening and care practices and stigmatize women ${ }^{19,30,35,37}$. Cultural variations in mental health stigma underlie the importance of examining attitudes to mental health among midwives in their context of care ${ }^{19,25,35}$. Research has highlighted the importance of healthcare professionals including midwives having awareness of their attitudes and potentially stigmatising views towards women with mental illness ${ }^{25}$.

The MICA 4 scale used in this study is applicable to professionals within any healthcare discipline where a higher MICA score indicates more negative stigma-related mental health attitudes. This is the first study to use the MICA scale with midwives and the mean MICA-4 score 36.31 (SD=7.6), can be 
compared to the findings of international studies that have examined a variety of healthcare professionals' attitudes to severe mental illness using the MICA scale. Gabbidon et al. ${ }^{25}$ reported a slightly lower mean MICA v4 score of 34.55 ( $\mathrm{SD}=7.11, \mathrm{n}=183$ ) for nursing students in their foundation year of an English university. Likewise, Vendsborg et al. ${ }^{38}$ examined staff's attitudes to a person with schizophrenia at two psychiatric units in Copenhagen and reported a slightly higher mean MICA score of 37.3. Li et al. ${ }^{39}$ examined community mental health staff's attitudes in China to mental illness using the MICA scale and total scores were 51.69 (SD = 6.94), scores ranged from 2968. In the current study, the MICA score suggests positive attitudes to persons with severe mental illness; however, $65 \%$ of midwives reported that they would be hesitant to disclose a personal diagnosis of mental illness to friends and colleagues suggesting that they perceive a stigma associated with mental illness.

Hauck et al. ${ }^{20}$ used two separate components to examine Australian midwives' attitudes to mental health. The first component addressed common beliefs and/or misconceptions about a midwife's role in handling PMH needs and the Stereotype Content Model (SCM) was used to assess how different groups of childbearing women were perceived by midwives in terms of their competence/capability and warmth/friendliness. The findings suggest a range of positive attitudes towards women who experience mental health disorders though the results of the SCM indicated pervasive negative stereotyping where women with a mental health disorder were judged as being low in warmth and competence. Likewise, in a study of Australian midwives, more than $60 \%$ identified negative responses to women with mental illness and reported that most of the time the midwives they worked with avoided women with mental illness ${ }^{40}$.

Similarly, nursing studies have explored attitudes to mental health. A recent integrative review that examined nurses' attitudes toward mental illness across twenty countries ${ }^{41}$ found that nurses tend to have mixed attitudes toward different aspects of mental illness, comparable to attitudes among the public and which may partly be explained by different culture beliefs. Furthermore, in a study that examined attitudes of qualified versus student mental health nurses towards an individual diagnosed 
with schizophrenia found that negative attitudes exist among mental health nurses in relation to their patients and that greater experience was associated with more positive attitudes ${ }^{35}$.

The impact of HCPs mental health related stigma is emerging in the literature as a barrier toward help seeking behaviour of women with mental health problems ${ }^{41,42,43,44}$. Systematic reviews that have examined women's experiences of PMHPs have highlighted the importance of receiving care from non-judgemental healthcare professionals ${ }^{42,43}$. Women also reported feeling stigmatised by midwives where they encountered what they perceived as surveillance and monitoring of their psychological distress and believed that midwives were sceptical of their ability to care for their infant ${ }^{30}$. Stigma is a barrier to effective perinatal care which midwives have the most potential to influence or change ${ }^{45}$. Midwives have a role to play in reducing PMH stigma but it is important that they have support to reduce their own stigma ${ }^{46}$. In the current study, the majority of midwives would not mind working with a colleague with severe mental illness but would be hesitant to disclose a personal diagnosis of mental illness. Healthcare professionals are among a group identified as being disproportionately deterred by stigma ${ }^{44}$.

PMH education needs to extend beyond improving knowledge of the spectrum of PMHPs and combat healthcare professionals' own tendencies to stigmatise ${ }^{39,46}$. Education regarding mental illness could potentially promote positive attitudes by midwives towards women with mental health problems ${ }^{41}$. Attitudinal barriers also require positive systematic changes such as a health culture that routinely screens, refers and engages women with PMHPs in treatment and this in turn can reciprocally impact on midwives' attitudes ${ }^{45}$. Opportunities should be provided for midwives to explore their own personal attitudes, assumptions and stereotypes towards women with severe PMHPs with the objective of reducing negative attitudes ${ }^{35}$. Furthermore, clinical supervision and support pathways that incorporate reflection and discussion of personal and professional issues that may arise in caring for women with severe mental illness should be available to midwives ${ }^{35}$. Social contact interventions in which women who have experienced a PMHP share their experiences of engaging in maternity 
services may alert midwives to how personal attitudes and behaviour may impact on the woman's experience of care $^{35}$.

\section{Strengths and limitations}

The survey used internationally psychometrically validated scales to obtain information from midwives across seven maternity services. The findings of the current study must be viewed in the context of its methodological limitations. Limitations include the response rate and whilst $36.7 \%$ was acceptable for a general survey, results should be interpreted with caution and despite the anonymous nature of the survey, the response rate may be reduced due to the sensitivity of the topic. No information was collected about non-responders and it is possible that those with an interest in mental health related issues participated in this study and were attitudinally and/or behaviourally different to those who choose not to participate. Social desirability responses may be more likely to occur with sensitive questioning around attitudes to persons with severe mental illness present in this current study.

\section{Conclusion}

If midwives are to be effective in supporting women who experience PMHPs and their families, they must have access to ongoing education and training, have organisational support that recognises the importance of PMH and the time that midwives will require to address this issue, and have access to appropriate referral pathways with a variety of options. Training must also focus on developing midwives' PMH cultural competence. Professional development opportunities need to provide midwives with an opportunity to explore their own personal attitudes and potentially stigmatising views towards women who experience severe PMHPs with the objective of reducing negative stereotypes and attitudes. Development of an attitude scale specific to PMH and for use with healthcare professionals working with women and their families would be useful so that international comparisons can be made and that the impact of education on changes in attitudes can be assessed. 
4.

\section{Conflict of interest}

The authors do not have any conflict of interest.

\section{Acknowledgements}

The authors would like to thank the midwives who participated in the study. There has been no financial assistance with this project.

\section{References}

1. Wisner KL, Austin M-P, Bowen A, Cantwell R, Glangeaud-Freudenthal NM-C. International Approaches to Perinatal Mental Health Screening as a Public Health Priority. In: Milgrom J, Gemmill AW, editors. Identifying Perinatal Depression and Anxiety Evidence-Based Practice in Screening, Psychosocial Assessment, and Management. Oxford: Wiley Blackwell; 2015. P.193-209.

2. Austin MP, Priest SR, Sullivan EA. Antenatal psychosocial assessment for reducing perinatal mental health morbidity. Cochrane Database of Systematic Reviews 2008, Issue 4. Art. No: CD005124. DOI:10.1002/14651858.CD005124.pub2.

3. Leahy-Warren P, McCarthy G, Corcoran P. Postnatal Depression in First-Time Mothers: Prevalence and Relationships Between Functional and Structural Social Support at 6 and 12 Weeks Postpartum. Archives of Psychiatric Nursing 2011; 25(3):174-184.

4. Howard LM, Ryan EG, Trevillion K, Anderson F, Bick D, Bye A, Byford S, O'Connor S, Sands P, Demilew J, Milgrom J, Pickles A. Accuracy of the Whooley questions and the Edinburgh Postnatal Depression Scale in identifying depression and other mental disorders in early pregnancy. The British Journal of Psychiatry 2018; 212:50-56. 
5. Knight M, Nair M, Tuffnell D, Shakespeare J, Kenyon S, Kurinczuk JJ (Eds.) on behalf of MBRRACEUK. Saving Lives, Improving Mothers' Care Lessons learned to inform future maternity care from the UK and Ireland Confidential Enquiries into Maternal Deaths and Morbidity 2013-2015. Oxford: National Perinatal Epidemiology Unit, University of Oxford 2017.

6. Martin CR. Perinatal Mental Health: A Clinical guide. Cumbria: M\&K Publishing; 2012.

7. Grote NK, Bridge JA, Gavin AR, Melville JL, Iyengar S, Katon WJ. A Meta-analysis of Depression During Pregnancy and the Risk of Preterm Birth, Low Birth Weight, and Intrauterine Growth Restriction. Arch Gen Psychiatry 2010; 67(10):1012-1024.

8. Kingston D, Tough S, Whitfield H. Prenatal and postpartum maternal psychological distress and infant development: a systematic review. Child Psychiatry Hum Dev 2012; 43 (5):683714. PMID 2240727

9. Wee KY, Skouteris H, Pier C, Richardson B, Milgrom J. Correlates of ante-and postnatal depression in fathers: a systematic review. J Affect Disord 2011; 130 (3):358-377. PMID 20599275

10. beyondblue. Clinical practice guidelines for depression and related disorders - anxiety, bipolar disorder and puerperal psychosis - in the perinatal period. A guideline for primary care health professionals. Melbourne: beyondblue: the national depression initiative; 2011.

11. National Institute for Health and Clinical Excellence. Antenatal and postnatal mental health: Clinical management and service guidance. NICE clinical guideline 45. 2014 Dec; guidance.nice.org.uk/cg192.

12. Khan L. Falling through the gaps: perinatal mental health and general practice. UK: Centre for Mental Health; 2015.

13. Austin M-P, Marce International Society position statement on psychosocial assessment and depression screening in perinatal women. Best Practice \& Research Clinical Obstetrics and Gynaecology 2014; 28 (2014): 179-187. 
14. Brealey SD, Hewitt C, Green JM, Morrell J, Gilbody S. Screening for postnatal depression: is it acceptable to women and healthcare professionals? A systematic review and meta-synthesis. Journal of Reproductive and Infant Psychology 2010; 28(4):328-344.

15. Reilly N, Harris S, Loxton D, Chojenta C, Forder P, Milgrom J, Austin MP. Referral for Management of Emotional Health Issues During the Perinatal Period: Does Mental Health Assessment Make a Difference?. Birth 2013; 40 (4):297-306. PMID 24344711

16. Jomeen J, Glover LF, Davies SA. 'Midwives’ Illness Perceptions of Antenatal Depression'. British Journal of Midwifery 2009; 17 (5):296-303.

17. Rollans M, Schmied V, Kemp L, Meade T. 'We just ask some questions...' the process of antenatal psychosocial assessment by midwives'. Midwifery 2013; 29:935-942.

18. Jones CJ, Creedy DK, Gamble JA. Australian midwives' attitudes towards care for women with emotional distress. Midwifery 2012; 28 (2) 216-221. PMID 21342738

19. Noonan M, Doody O, Jomeen J, Galvin R. Midwives' perceptions and experiences of caring for women who experience perinatal mental health problems: An integrative review. Midwifery 2017; 45:56-71.

20. Hauck YL, Kelly G, Dragovic M, Whittaker P, Badcock JC. Australian midwives knowledge, attitudes and perceived learning needs around perinatal mental health. Midwifery 2015; 31:247-255

21. STROBE -Strengthening the Reporting of Observational Studies in Epidemiology guidelines

22. Martin CR, Jomeen J, Jarrett P. The development and initial validation of the Perinatal Mental Health Awareness (PMHA) scale in student midwives. Journal of Midwifery and Reproductive Health 2017; 5(4), 1021-1031. DOI: 10.22038/JMRH.2017.9251.

23. Jomeen J, Glover L, Jones C, Garg D, Marshall C, Martin C. Adapting the Illness Perception Questionnaire - Revised (IPQ-R) to assess practitioner perceptions of perinatal mental health problems (PMHP). Society for Reproductive and Infant Psychology Conference. Valetta, Malta; 2014. 
24. Jomeen J, Jarrett P, Martin CR. Professional issues in maternal mental health scale (PIMMHS): The development and initial validation of a brief and valid measure. Unpublished results.

25. Gabbidon J, Clement S, van Nieuwenhuizen A, Kassam A, Brohan E, Norman I, Thornicroft G. Mental Illness: Clinicians' Attitudes (MICA) Scale - Psychometric properties of a version for healthcare students and professionals. Psychiatry Research 2013; 206:81-87.

26. Whooley MA, Avins AL, Miranda J, Browner WS. Case-finding instruments for depression: Two questions are as good as many. J Gen Intern Med 1997; 12:439-45.

27. Cox JL, Holden JM, Sagovsky R. Detection of postnatal depression. Development of the 10item Edinburgh Postnatal Depression Scale. The British Journal of Psychiatry 1987; 150 (6): $782-786$

28. Jones, C. J, Creedy, D. K, Gamble, J. A. Australian midwives awareness and management of antenatal and postpartum depression. Women and Birth 2012; 25: 23-28.

29. Buist A, Bilszta J, Milgrom J, Barnett B, Hayes B, Austin M-P. Health professional's knowledge and awareness of perinatal depression: Results of a national survey. Women \& Birth 2006; 19: 11-16.

30. Higgins A, Tuohy T, Murphy R, Begley C. Mothers with mental health problems: Contrasting experiences of support within maternity services in the Republic of Ireland. Midwifery 2016; 36: $28-34$.

31. Cox J. Foreword. In: Milgrom J, Gemmill AW, Editors. Identifying Perinatal Depression and Anxiety Evidence-Based Practice in Screening, Psychosocial Assessment, and Management. Oxford: Wiley Blackwell; 2015. p. xvi-xvii.

32. Milgrom J, Gemmill AW. Current Issues in Identifying Perinatal Depression: An Overview. In: Milgrom J, Gemmill AW, Editors. Identifying Perinatal Depression and Anxiety EvidenceBased Practice in Screening, Psychosocial Assessment, and Management. Oxford: Wiley Blackwell; 2015. p.1 
33. Higgins A, Carroll M, Gill A, Downes, Monahan M. Perinatal Mental Health Care: Best Practice Principles for Midwives, Public Health Nurses and Practice Nurses. Dublin: Health Service Executive; 2017.

34. Morrell J.C., Cubison J, Ricketts T, Williams AS, Hall P. Training Health-Care Professionals for the Assessment and Management of Perinatal depression and Anxiety. Milgrom J, Gemmill AW, editors. Identifying Perinatal Depression and Anxiety Evidence-Based Practice in Screening, Psychosocial Assessment, and Management. Oxford: Wiley Blackwell; 2015. p. 210-227.

35. Linden M, and Kavanagh R. Attitudes of qualified vs. student mental health nurses towards individuals diagnosed with schizophrenia. Journal of Advanced Nursing 2012; 68(6), 13591368. doi: 10.1111/j.1365-2648.2011. 05848.x

36. Reavley NJ, Jorm AF. Recognition of mental disorders and beliefs about treatment and outcome: findings from an Australian national survey of mental health literacy and stigma. Aust NZ J Psychiatry 2011; 45(11), 947-956.

37. Fonti S, Davis D, Ferguson S. The attitudes of healthcare professionals towards women using illicit substances in pregnancy: A cross-sectional study. Women and Birth 2016; 29: 330-335.

38. Vendsborg P, Bratbo J, Dannevang A, Hagedorn-Moller J, Kistrup K, Lindhardt A, Nordentoft M. Staff attitudes towards patients with schizophrenia. Danish Medical Journal $2013 ; 60 / 10$.

39. Li J, Li J, Thornicroft G, Huang Y. Levels of stigma among community mental health staff in Guangzhou, China. BMC Psychiatry 2014; 14:231.

40. McCauley K., Elsom S, Muir-Cochrane E, Lyneham J. Midwives and assessment of perinatal mental health. Journal of Psychiatric and Mental Health Nursing 2011; 18: 786-795.

41. De Jacq K, Norful AA, Larson E. The Variability of Nursing Attitudes Toward Mental Illness: An Integrative Review. Archives of Psychiatric Nursing 2016; 30:788-796.

42. Megnin-Viggars O, Symington I, Howard LM, Pilling S. Experience of care for mental health problems in the antenatal or postnatal period for women in the UK: a systematic review and 
meta-synthesis of qualitative research. Arch Womens Ment Health 2015; 18: 745-759. DOI 10.1007/s00737-015-0548-6.

43. Dolman C, Jones I, Howard LM. Pre-conception to parenting: a systematic review and metasynthesis of the qualitative literature on motherhood for women with severe mental illness. Arch of Womens Ment health 2013; 16: 173-196. doi.10.1007/s00737-013-0336-0.

44. Clement S, Schauman O, Graham T, Maggioni F, Evans-Lacko S, Bezborodovs N, Morgan C, Rusch N, Brown JSL, Thornicroft G. What is the impact of mental health-related stigma on help-seeking? A systematic review of quantitative and qualitative studies. Psychological Medicine 2015; 45: 11-27.

45. Buist A, O’Mahen H, Rooney R. Acceptability, Attitudes and Overcoming Stigma. In: Milgrom J, Gemmill AW, Editors. Identifying Perinatal Depression and Anxiety EvidenceBased Practice in Screening, Psychosocial Assessment, and Management. Oxford: Wiley Blackwell; 2015. p. 51-62.

46. Li J, Li J, Thornicroft G, Yang H, Chen W, Huang Y. Training community mental health staffin Guangzhou, China: evaluation of the effect of a new training model. BMC Psychiatry $2015 ; 15: 263$. 